\title{
Nursing Care of The Third and Fourth Stages of Labor : Protocol Of Care
}

\author{
Eman W. I.* Ragaa A. A.** Amal A.O.*** Afaf M.E. **** \\ *B.SC. Nursing, faculty of nursing, Tanta University ** Maternal and Obstetrics, Faculty of \\ Nursing, Cairo University*** Maternal and Newborn Health Nursing, Faculty of Nursing, Benha \\ University $* * * *$ Maternal and Newborn Health Nursing, Faculty of Nursing, Benha University.
}

\begin{abstract}
Aim: Aim of this study is to determine the effect of nursing protocol on the third and fourth stages of labor. Setting: The study was conducted at obstetric and gynecology department in benha university hospital. Design: A quasi experimental design was utilized. Sampling: A purposive sample included (80) nurse. Tools: The tools of data collection were interviewing questionnaire sheet and observational checklist. Results:. More than two thirds of the studied nurses had poor knowledge regarding third and fourth stage of labor was poor in pre intervention test and improved to more than three quarter in post intervention test $\mathrm{P}$ value $<0.001 * *$.. Majority of nurses had unsatisfactory practices in pre test as compared with post intervention test $\mathrm{P}$ value $<0.001 * *$.Conclusion: More than two thirds of the studied nurses had poor score of knowledge in pre test and improved to more than three quarter had good knowledge in post test. Majority of studied nurses had unsatisfactory practices and in pre intervention test as compared with post intervention test and majority of them had satisfactory practice. Recommendation: Educational program for nurses to upgrade their knowledge and practices regarding the third and fourth stages of labor.
\end{abstract}

Key words: Third and fourth stages of labor, nursing care.

Introduction

Birth is an immensely important, and the care that a woman receives during labor has the potential to affect on both physically and emotionally in the short and longer term.(Iravani, etal., 2015).

The World Health Organisation (WHO), (2011), stated that the normal birth as spontaneous in onset, low risk at the start of labour and remaining so throughout labour and delivery. The infant is born spontaneously in the vertex position between 37 and 42 completed weeks of pregnancy. After birth both mother and infant are in good condition.
The major complication associated with third stage of labor is postpartum hemorrhage $(\mathrm{PPH})$, retained placenta and uterine inversion. postpartum hemorrhage is generally defined as blood loss greater than $500 \mathrm{ml}$ within the first 24 hours after birth, while in severe condition blood loss is greater than or equal to $1000 \mathrm{ml}$ within 24 hours. postpartum hemorrhage is a major cause of maternal mortality and morbidity, particularly in developing countries, where most pregnancy related deaths are associated with hemorrhage. It may result from failure of the uterus to contract adequately (Yaekob, etal., 2015). 
The main measure to reduce maternal mortality and morbidity is the nurse who is in key position by disseminating knowledge regarding third and fourth stage of labor ensuring and providing proper service to enhance woman's role in the implementation of efficient self care practices and become more independent.(Lorraine H., 2012)

Nurses have a crucial task in labor, women who received care from nurses had higher self esteem and self efficacy and empowerment, they were also able to achieve a sense of mastery during labor and the child bearing period, which are valuable to women's birth experience. (Farahat, etal., 2015).

\section{Significance of the study}

Worldwide, the majority of maternal and newborn deaths occur around the time of birth, typically within the first 24 hours after labor. Most of these deaths are preventable, (WHO, 2015). The third and fourth stage of labor is a crucial period because many life threatening complications can accompany this period (Kaur, et al., 2014).

Egypt has an improved but relatively high maternal mortality ratio of 84 maternal deaths per 100,000 live births, although $60 \%$ of births are medically assisted and $49 \%$ are facility based. And PPH remains the leading cause contributing to $27 \%$ of maternal deaths, with poor obstetric management cited as the most frequent avoidable factor, contributing to $43 \%$ of maternal deaths (Dupont, et al., 2014). According to(WHO, 2015) maternal mortality rate in Egypt become 33 maternal deaths per 100,000 live births.

\section{Aim of The Study}

Aim of this study is to determine the effect of nursing protocol on the third and fourth stages of labor.
Research Hypothesis:-

-Nurses who received the protocol of nursing care regarding the third and fourth stage of labor showed remarkable improvement in their knowledge and practices than those who don't.

\section{Materials and methods:}

\section{Design:} utilized .

A quasi experimental design was

\section{Setting:}

The present study was conducted at labor and post- partum unit of obstetrics and gynecological department at Benha University Hospital.which provide care during pregnancy, labor, postpartum.

\section{Subject:}

- Sample type: - Convenient sample.

- Sample size:-(80) nurses.

Sampling technique:All nurses working in the obstetrics and

\section{Tools of data collection:}

1-Interviewing questionnaire sheet: Which include two parts:

Part I:It was designed to collect data about the socio- demographic characteristics of nurses involved in the study as (age, educational level, residence, years of experiences).

Part II: It was designed to assess the nurses' knowledge regarding the third and fourth stages of labor.

Scoring system for the knowledge: 
A score for each answer was given as follows:

$\begin{array}{ll}\text { - Correct answer scored } & =(3) . \\ \text { - Incorrect answer scored } & =(2) . \\ \text { - Unknown scored answer } & =(1) .\end{array}$

As well as nurse's total knowledge score was classified as the following:

The knowledge was considered good if the percentage of total knowledge score equals more than $75 \%$ and considered average if the percentage of total knowledge score equals $50-75 \%$, and considered poor if the percentage of total knowledge score equals less than $50 \%$.

2 -An observational checklist: was used to assess the nursing care giving to the women during third and fourth stages of normal labor pre and post intervention.

-The observational checklist which include practical nursing procedures that must be done in the third and fourth stage of labor.

\section{checklist: \\ Scoring system of observational}

An observation score was graded as:

- If done correct scored (3).

- If done incorrect done scored (2).

-If not done scored (1).

As well as nurse's total practice score was classified as the following:

-Satisfactory if percentage of the total performance score equals or more than $75 \%$.

- Unsatisfactory if the percentage of total performance score is less than $75 \%$.

\section{Ethical considerations:}

-Approval would be obtained orally from the nurses before intervention.

- The purpose of the study would be explained.

-The nurses were assured that the data collected would be confidential and would be used only for the research purpose.

- Each nurse would be free to withdraw at any time of the study.

\section{II-Methods:}

\section{-Operational design:}

\section{- Preparatory phase:}

A review of the current and past available literature, using textbooks, articles, magazines and internet search was done to be acquainted with, and oriented about aspects of the research problem, as well as to assist in the development of data collection tools and the preparation of the protocol of care.

\section{- Pilot study:}

The pilot study was carried out for $(10 \%)$ of total sample (8 nurses) for clarity and reliability of the study tools, then there is no modifications was done and those nurses weren't excluded from the study sample.

\section{- Field work:}

The actual field work was carried out from the beginning of March 2015 to the end of november 2015. The researcher attend to the labor and postpartum department 3 days per week, started from 9.0 A.M to 3P.M.

- The researcher introduced herself to each nurse then clarify and explain the aim of 
the study to gain their trust and confidence.

- The researcher administrated questionnaire for all nurses to collect data as pre test (assessment phase), each questionnaire take about 25-30 minute.

- Based on results obtained from the pre test the (assessment phase), the researcher identify the shortage and gaps of nurses knowledge and practice during the third and fourth stage of labor.

- The researcher designed protocol of care according to (the nurses needs and shortage of knowledge and practices about the third and fourth stage of labor), the researcher apply the protocol of care in the form of sessions and handout (implementation phase).

- The session divided into 4 session (two session concerning to theoretical part and the others concerning to the practical part) according to the nurses time space and their work schedule.

- Total time for all sessions to each nurse took about 45: 60 minutes. At the beginning of the first session nurse were oriented with the protocol of care contents and the handout was distributed to all nurses in the first day of starting implementation of the protocol of care after explanation of all items.

- $\quad$ Each nurse was informed about the time of the next sessions at the end of session. The subsequent session started by a feedback about the previous session and the objectives of the new sessions.

- At the end of each sessions nurses questions were discussed to correct any misunderstanding. Different methods of teaching were used such as discussion, demonstration, re demonstration. Instructional media included video contain all content of protocol of care and handouts about third and fourth stage of labor .

- After implementation of the protocol of care the nursing care of third and fourth stage of labor was evaluated as post test by using the same forms of tools which used in the pre test(evaluation phase).

\section{Statistical design:}

Data was verified prior to computerized entry. The Statistical Package for Social Sciences (SPSS version 20.0) was used for that purpose followed by data tabulation and analysis. Descriptive statistics were applied (e.g, mean , standard deviation, frequency and percentage). Test of significance( $t$ test , Chi-square) Pearson correlation coefficients were used paired t test was used to compare mean score at the pre and post intervention. A significant level value was considered when $>$ p 0.05 . And a highly significant level value was considered when $\mathrm{p}<0.001$

\section{Limitation of the study:}

Sometimes some nurses (3 nurses) refuse to participate in the session because they had a lot of duties and work in this time. 
Results:

Table (1): Distribution of studied sample according to the personnel characteristics No=80.

\begin{tabular}{|c|c|c|}
\hline Variable & No & $\%$ \\
\hline \multicolumn{3}{|l|}{ Age in years } \\
\hline $20-25$ & 10 & 12.5 \\
\hline $26-30$ & 42 & 52.5 \\
\hline $31-35$ & 23 & 28.8 \\
\hline Mean \pm SD & \multicolumn{2}{|c|}{$26.39 \pm 5.08$} \\
\hline \multicolumn{3}{|l|}{ Residence } \\
\hline Rural & 39 & 48.8 \\
\hline Urban & 41 & 51.3 \\
\hline \multicolumn{3}{|l|}{ Educational qualification } \\
\hline Secondary nursing education & 33 & 41.3 \\
\hline Technical nursing education & 23 & 28.8 \\
\hline Baccular of nursing & 24 & 30.0 \\
\hline \multicolumn{3}{|l|}{ Years of experience } \\
\hline $1-5$ & 45 & 56.3 \\
\hline $6-10$ & 27 & 33.8 \\
\hline$>10$ & 8 & 10.0 \\
\hline Mean \pm SD & \multicolumn{2}{|c|}{$19.87 \pm 4.78$} \\
\hline
\end{tabular}

Table (1) showed that the mean age of studied nurse (26.39 \pm 5.08$)$.more than half of them were live at urban area and had1 to 5 years of experience with Mean \pm $\mathrm{SD}(19.87 \pm 4.78)$. Further more less than half of them(41.3\%) had a secondary nursing education. 
Eman W., Ragaa A., Amal A., Afaf M.

Table (2): Distribution of studied sample according to mean score of knowledge regarding third stage of labor $\mathrm{N}=80$.

\begin{tabular}{|l|c|c|c|c|c|c|c|c|}
\hline \multirow{2}{*}{ Variable } & \multicolumn{3}{|c|}{$\begin{array}{c}\text { Before } \\
\text { intervention }\end{array}$} & \multicolumn{2}{c|}{$\begin{array}{c}\text { After } \\
\text { intervention }\end{array}$} & \multirow{2}{*}{ Paired t test } & P value \\
\cline { 2 - 8 } & \multicolumn{3}{|c|}{ Mean \pm SD } & \multicolumn{2}{c|}{ Mean \pm SD } & \\
\hline Definition of the third stage of labor. & 0.51 & \pm & 0.76 & 1.83 & \pm & 0.37 & -14.96 & $<0.001^{* *}$ \\
\hline Duration of the third stage of labor. & 0.15 & \pm & 0.35 & 1.02 & \pm & 0.27 & -16.99 & $<0.001^{* *}$ \\
\hline Mechanisms of placenta delivery $\cdot$ & 1.37 & \pm & 0.53 & 2.00 & \pm & 0.00 & -10.41 & $<0.001^{* *}$ \\
\hline Importance of placenta examination. & 2.11 & \pm & 0.85 & 2.92 & \pm & 0.26 & -8.77 & $<0.001^{* *}$ \\
\hline Signs of placenta separation. & 2.42 & \pm & 1.58 & 5.71 & \pm & 0.45 & -19.04 & $<0.001^{* *}$ \\
\hline $\begin{array}{l}\text { Complication of the third stage of } \\
\text { labor. }\end{array}$ & 2.17 & \pm & 1.64 & 4.77 & \pm & 0.42 & -14.42 & $<0.001^{* *}$ \\
\hline Anti tocolytic drug. & 1.56 & \pm & & & & & & \\
\hline Side effect of antitocolytic drugs. & 1.33 & \pm & 0.52 & 1.90 & \pm & 0.30 & -10.07 & $<0.001^{* *}$ \\
\hline
\end{tabular}

**A highly statistical significant difference $(\mathrm{P}<0.001)$

Table (2) showshighly statistical significant difference between nurses knowledge regarding third stage of laborpre and post intervention $\mathrm{p}$ value $<0.001 * *$.

Figure (1): Percentage distribution of total knowledge score of the studied sample regarding third and fourth stage of labor $\mathrm{N}=80$.

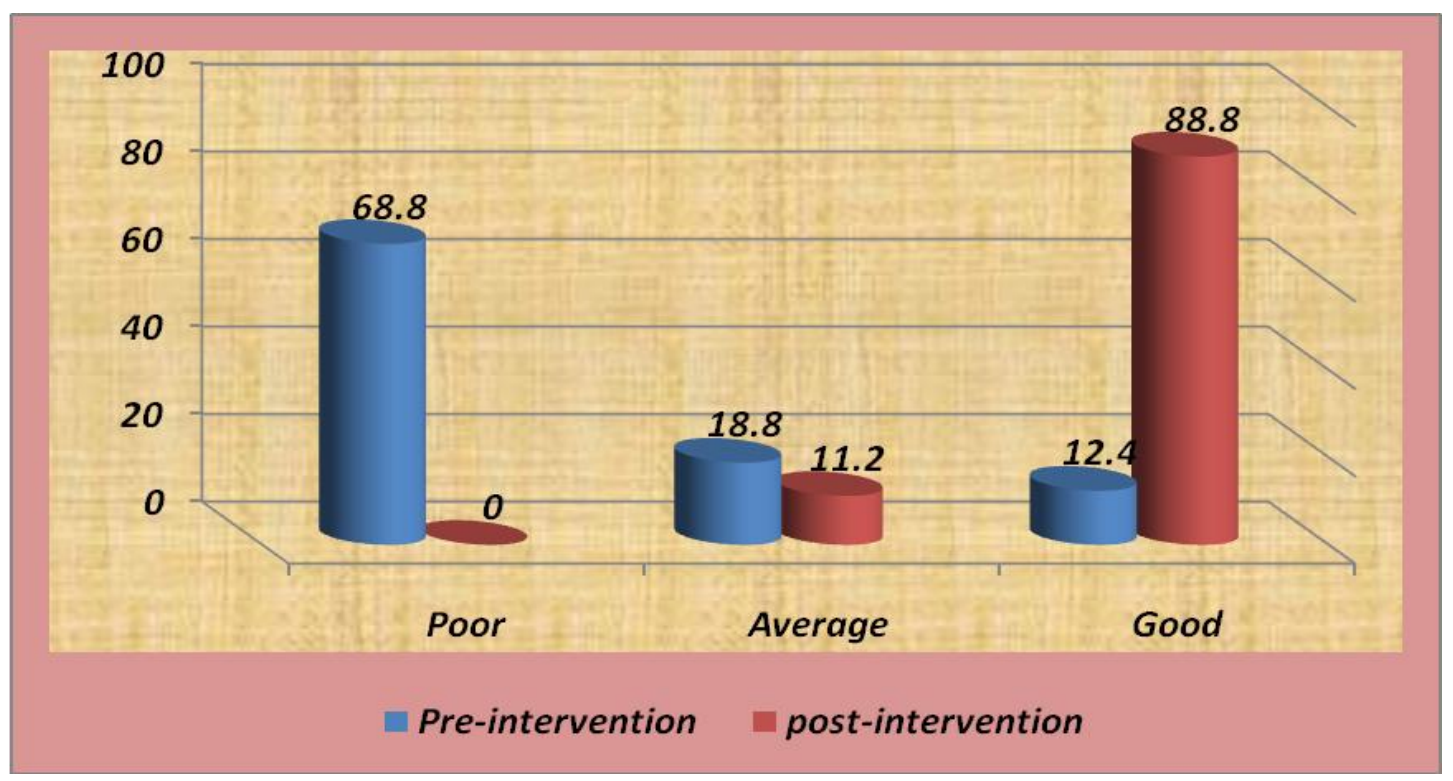


Table (11): Relation of studied sample total practice score in relation to their personnel characteristics at post intervention phase. $\mathrm{N}=80$.

\begin{tabular}{|c|c|c|c|c|c|c|}
\hline \multirow[t]{2}{*}{ Variable } & \multicolumn{2}{|c|}{$\begin{array}{l}\text { Unsatisfactory } \\
\qquad \mathbf{N}=\mathbf{8}\end{array}$} & \multicolumn{2}{|c|}{$\begin{array}{l}\text { Satisfactory } \\
\qquad \mathbf{N}=72\end{array}$} & \multirow[t]{2}{*}{$\begin{array}{c}\text { Chi square } \\
\text { test }\end{array}$} & \multirow[t]{2}{*}{ P value } \\
\hline & No & $\%$ & No & $\%$ & & \\
\hline \multicolumn{5}{|l|}{ Age in years } & \multirow{4}{*}{1.17} & \multirow{4}{*}{$>0.05$} \\
\hline $20-25$ & 2 & 13.0 & 10 & 14.8 & & \\
\hline $26-30$ & 3 & 43.5 & 40 & 5.5 & & \\
\hline $31-35$ & 3 & 43.5 & 21 & 9.8 & & \\
\hline \multicolumn{5}{|l|}{ Residence } & \multirow{3}{*}{0.673} & \multirow{3}{*}{$>0.05$} \\
\hline Rural & 5 & 62.5 & 34 & 47.2 & & \\
\hline Urban & 3 & 37.5 & 38 & 52.8 & & \\
\hline \multicolumn{5}{|l|}{ Educational qualification } & \multirow{4}{*}{12.66} & \multirow{4}{*}{$<0.001^{* *}$} \\
\hline Secondary nursing education & 8 & 100.0 & 25 & 34.7 & & \\
\hline Technical nursing education & 0 & 0.0 & 23 & 31.9 & & \\
\hline Baccular of nursing & 0 & 0.0 & 24 & 33.3 & & \\
\hline \multicolumn{5}{|l|}{ Years of experience } & \multirow{4}{*}{3.62} & \multirow{4}{*}{$>0.05^{*}$} \\
\hline $1-5$ & 3 & 37.5 & 42 & 58.3 & & \\
\hline $6-10$ & 5 & 62.5 & 22 & 30.6 & & \\
\hline$>10$ & 0 & 0.0 & 8 & 11.1 & & \\
\hline
\end{tabular}

Table (11) revealed that there was a high significant relation between studied nurses' total practices and their qualification $\mathrm{p}$ value $<0.001 * *$ in post intervention.

\section{Discussion}

Concerning sociodemographic characteristics of studied nurses, the findings of this study showed that more than half of them had age group form (26 -30) years , were live at urban settings and had 1 to 5 years of experience .Furthermore, less than half of them had a secondary nursing education. These findings in the same line with (Abd El Fattah \&Zein El Dein, 2012 )who found that most of nurses age between 26-30 years and about half of the studied nurses have $1-5$ years of experience.
In relation to nurses knowledge regarding the third and fourth stages of labor, the current study revealed that there was a highly statistical significant difference between their knowledge about third stage of labor pre and post intervention, $\mathrm{P}$ value $<0.001$.

This study in the same line with (Muzeya,2015) who found that a majority of the participants answered incorrectly the question on the active management and physiology of the third stage of labor pre intervention. This study also, agree with (Satwe et al.,2016)who revealed that nurses knowledge in pre test regarding third stage 
of labor more than half of nurses had average knowledge,(20\%) had good knowledge. While more than two thirds of nurses in posttest had good knowledge , and (12.5\%) had poor knowledge. This study also in contrast with(Ramidhani,2011) who found that every nurse knew all the knowledge of the third stage of labor and uterotonic recommended for AMTSL (100\%), and each question was scored correctly by more than half of nurses pre test and this is due to frequent periodical training and courses regarding third and fourth stages of labor.

Regarding nurses' total practice score in relation to their personnel characteristics this study revealed that there was a high significant relation between studied nurses' total practices and their qualification $\mathrm{p}$ value $<0.001 * *$ in post intervention and this study agree with (Ahmed, etal., 2014) they revealed that, there was statistical significant relation between nurses' practice and years of experience ( $p>0.05)$. Actually, this may be due to years of experience enable them to master skills competently and agree with ( Rasheid\& Ali , 2010) who revealed that there was a high significant association between nurse's practices and their educational level $\mathrm{p}$ value $>0.05$.

This study differ with (Satwe, 2016)who approved that there was no relation between nurses practices and general characteristics $P$ value at 0.05 level.

\section{Conclusion:}

The protocol of care had positive effect on nurses knowledge regarding third and fourth stages of labor. In addition to that a remarkable improvement on nurses practices after implementation of protocol of care as compared to pre intervention. More than two thirds of the studied nurses had poor knowledge regarding third and fourth stages of labor pre intervention and their knowledge improved to more than three quarter in post intervention test $\mathrm{P}$ value $<0.001^{* *}$. Hence, practices regarding the third and fourth stage for labor showed that majority of them had unsatisfactory practices and minority of them had satisfactory practices $\mathrm{P}$ value $<0.001 * *$.

\section{Recommendations}

Based on the finding of this study, the following recommendations are made:

1-Developing periodical educational program for nurses to upgrade their knowledge and practices regarding the third and fourth stages of labor.

2-All nurses in obstetric department should be trained to provide adequate and effective nursing care in third and fourth stage of normal labor .

\section{References}

Abd El Fattah N. and Zein El Dein N.A.,(2012): Assessment of Quality of Nursing Care Provided Immediately After Birth At University Hospital, Maternal and Newborn Health Nursing, Faculty of Nursing, Helwan University, Egypt. Pediatric Nursing Faculty of Nursing Menoufia University, Egypt Life Science Journal ;9(4) http://www.lifesciencesite.com.

Ahmed R.M., Mohamed A. R. and Mahmoud F.Sh. etal., (2014):Quality of Nursing Care Provided for Neonates with Tracheoesophageal Fistula, Ain Shams University Journal of Education and Practice www.iiste.orgISSN 2222-1735 (Paper) ISSN 2222-288X (Online)Vol.5, No.3, 2014, pp.186.

Dupont C., Ducloy- Bouthors A.S. and Huissoud C. (2014): [Clinical and pharmacological procedures for the prevention of postpartum haemorrhage in the third stage of labor.].J. GynecolObstetBiolReprod (Paris). Nov 6. 43(10):966-997. [Medline] 
Farahat H. A., Mohamed E. H., Abd Elkader Sh. and El-NemerA.(2015): Effect of Implementing A Birth Plan on Womens' Childbirth Experiences and Maternal \& Neonatal Outcomes, Technical Institute of Nursing, Faculty of Nursing , Mansoura University Egypt, Maternal and Newborn Health Nursing Department, Faculty of Nursing, Cairo University Egypt. Journal of Education and Practice www.iiste.org ISSN 2222-1735 ISSN 2222-288X Vol.6, No.6, 24.

Hassan, H. (2011): Nursing performance regarding infection control for patient undergoing open heart surgery, Master thesis, Faculty of nursing, Benha university.

Iravani M., Mohsen Janghorbani M., Zarean E. and Bahrami M., (2015): An overview of systematic reviews of normal labor and delivery management Iranian Journal of Nursing and Midwifery Research | MayJune | Vol. 20 | Issue 3

Kaur N., Kaur S. \&Saha P. K., (2014): Nursing \& Midwifery Research Journal. Vol-10,No.1, Jan.

Lorraine H ., (2012):Orem "s Self Care Model, Haunted Coe College, Hannibal, Missouri NY: Penguin Books.

Muzeya F., (2015): Knowledge, attitudes and practices of nurse-midwives related to obstetric care at Thaba-Tseka district in Lesoth, University of south africa.

RasheidA.M. \& Ali R. M., (2010):Assessment of Nurse Midwives' Knowledge and Practices toward Second Stage of Labor,Iraqi Sci. J. Nursing, Vol. 23.
Ramadhani F., (2011):Midwives competency for implementation of active management of third stage of labor in Dar Es Salam municipal hospitals, Tanzania., Muhimbili University of Health and Allied Sciences September.

Satwe,( 2016): Effectiveness of Planned Teaching Programme on Knowledge Regarding Active Mangement of 3Rd Stage of Labour Among 4Th Year B.bsc Nursing Students of Krishna Institute of Nursing Sciences, Karad" Volume : 6 | Issue : 3 | March 2016 | ISSN - 2249555X | IF : 3.919 | IC Value : 74.50

World Health Organization(2011): Care in normal birth: a practical guide. Report of a technical working group. Safe motherhood practical guide. 1996 [cited 2011 January 27]; WHO/FRH/MSM/96.24. Available from: http://whqlibdoc.who.int/hq/1996/WHO_ FRH_MSM_96.24.pdf.

World Health Organization (2015): Pregnancy, Childbirth, Postpartum and Newborn Care, 3rd edition. A Guide for Essential Practice. Geneva: World Health Organization; 2015.ISBN-13:978-92-4154935-6.

Availableat:(www.who.int/about/licensin g/copyright_form/en/index.html).

Yaekob R. , Shimelis T., Henok A., and Lamaro T. (2015):Assessment Of Knowledge, Attitude, And Practice Of Midwives On Active Management Of Third Stage Of Labour At Selected HealthCenters Of Addis Ababa, Ethiopia, Mizan-Tepi University, Department of Nursing, Department of public health, Mizan-Tepi University and, Mizan-Tepi University Journal of Biology, www.iiste.org. ISSN 2224-3208 (Paper) ISSN 2225-093X (Online)Vol.5, No.11. 